\title{
Increased expression but not sensitivity to Fas/CD95 in glioblastoma cells depleted of mitochondrial DNA
}

\author{
BERTRAND C. LIANG \\ Pfenex Inc., San Diego, CA 92121; and Department of Medicine, Division of Human Medical Genetics, \\ University of Vermont College of Medicine, Burlington, VT 05405, USA
}

Received August 23, 2010; Accepted September 24, 2010

DOI: $10.3892 /$ etm.2010.158

\begin{abstract}
Mitochondria and Fas (CD95) play a role in tumorigenicity and apoptosis. In the present study, the functional relationship of mitochondria to Fas in mediating apoptosis was investigated. Glioblastoma cells (DBTRGO5MG, U87) were depleted of mitochondrial DNA (mtDNA) by treatment with ethidium bromide ( $\mathrm{Rho}^{-}$cells). Compared to $\mathrm{Rho}^{+}$cells, $\mathrm{Rho}^{-}$cells showed enhanced expression of Fas at the cell surface. Indeed, when $\mathrm{Rho}^{+}$cells were treated with mitochondrial respiratory chain complex inhibitors, Fas cell surface expression was noted to increase in a similar fashion to the depletion of mtDNA in both cell lines. However, when cells were evaluated for sensitivity to apoptosis using Fas-engagement, there was no difference between the $\mathrm{Rho}^{+}$ and Rho- cells in either cell line. By contrast, sensitivity to the cytotoxic agent cis-diammine-dichloroplatinum (cisplatin) was markedly increased in the Rho- cells, which expressed higher levels of cell surface Fas. Expression of Fas is increased with the depletion of mtDNA and respiratory complex inhibitors. However, this increase in expression does not necessarily translate to an increase in sensitivity to Fas-engagement, although there is an increase in the sensitivity of depleted cells to cytotoxic agents such as cisplatin.
\end{abstract}

\section{Introduction}

The role of mitochondria in the initiation of apoptosis in a number of studies is well documented (1-4). A reduction in mitochondrial transmembrane potential $(\Delta \Psi \mathrm{m})$ has been observed before the manifestation of nuclear apoptosis in certain cell types $(2,6-11)$, and nuclear apoptosis is inhibited by the stabilization of $\Delta \Psi \mathrm{m}$ (12-16). Additionally, mitochondria have been shown to harbor apoptogenic molecules, such as SMAC/DIABLO, HTRA2, cytochrome c, caspases and AIF (apoptosis-inducing factor), liberating such molecules into the cytosol to participate in the apoptotic process $(13,17-22)$.

Correspondence to: Dr Bertrand C. Liang, Pfenex Inc., 5501 Oberlin Drive, San Diego, CA 92121, USA

E-mail: bl@pfenex.com

Key words: mitochondria, Rho-, apoptosis pathways, cisplatin
By contrast, there are also reports of non- $\Delta \Psi$ m-dependent apoptosis (23), and studies indicating that mitochondria may be implicated in cell death suppression (24).

Fas (CD95), a type I transmembrane protein, consists of a cell surface receptor which transduces death signaling in a wide variety of cells upon stimulation by the Fas ligand or agonistic Fas antibodies (25-32). Changes in sensitivity to apoptosis mediated by Fas have been linked to a lack of cell surface Fas, overexpression of Bcl-2 family members, alteration in Fas intracellular signaling pathways, existence of Fas as a soluble protein, and expression of inhibitory factor(s) (28,33-39). However, it has been revealed that mere expression of Fas and $\mathrm{Bcl}-2$ (or Bcl-2-like molecules) is not predictive of biological responsiveness (40). Insensitivity of the Fas receptor to anti-Fas antibodies has been suggested to be a consequence of mitogen-activated protein kinase activation by the Fas receptor, which in turn interferes with caspase activation (41). It has also been demonstrated that Fas activates cells to die with or without the involvement of mitochondria (42).

Proteins encoded by mitochondrial DNA (mtDNA) are also implicated in the sensitivity to and execution of apoptosis, and may be critical in the initiation of growth arrest and apoptosis (43). By contrast, it has been shown that neither the apoptosis nor the protective effect of Bcl-2-type proteins depend on mitochondrial respiration (44-48). The elimination of mitochondrial oxidative metabolism has been found to inhibit not only tumor necrosis factor (TNF)-mediated cytotoxicity, but also to reduce the TNF-mediated gene regulatory signaling pathways (49). However, in cells depleted of mtDNA, a diminished tumorigenic phenotype and an increased sensitivity to cytotoxic drugs was noted (50-52). Other studies have reported that anti-mitochondrial agents chemosensitized glioblastoma (GBM) cells to cytotoxic agents (52).

The present study was undertaken to investigate the relationship between Fas and mitochondria in mediating apoptosis in GBM cells. The cell surface expression of Fas was evaluated in GBM cells upon the depletion of mtDNA, and in cells treated with mitochondrial respiratory chain complex inhibitors. Sensitivity to Fas antibodies and cis-diammine-dichloroplatinum (cisplatin) was determined in order to evaluate whether alterations in Fas expression lead to changes in response to the death inducers upon mtDNA depletion. The results suggest that the expression of cell surface Fas is not necessarily predictive of biological responsiveness. In addition, the response of 
cells to cytotoxic agents, such as cisplatin, is distinct to that of anti-Fas antibodies, despite similar alterations at the mitochondrial level.

\section{Materials and methods}

Cell culture. The GBM cell line DBTRG-O5MG was a gift from Dr Carol Kruse (Sanford Burnham Institute). The U87 cell line was purchased from ATCC (Rockville, MA, USA). The DBTRG-O5MG and U87 cell lines were cultured in RPMI-1640 supplemented with $10 \%$ FBS, 10,000 U/1 of penicillin-streptomycin, $4.5 \mathrm{~g} / 1$ glucose, $50 \mu \mathrm{g} / \mathrm{ml}$ uridine and $1 \mathrm{mM}$ pyruvate. Cells were maintained at $37^{\circ} \mathrm{C}$ in $5 \% \mathrm{CO}_{2}$. All culture mediums and supplements were obtained from Life Technologies Inc., Gaithersburg, MD, USA.

Generation of Rho cells. Rho- cells were generated from DBTRG-05MG and U87 cells by depletion of their mtDNA in culture medium containing $30 \mathrm{ng} / \mathrm{ml} \mathrm{EtBr}$ (Sigma Chemical Company, St. Louis, MO, USA). After at least 30 cell divisions, the Rho- status of the cells was established by determining the loss of mtDNA by PCR and by the auxotrophic dependence of the cells on pyruvate and uridine. Cells were harvested and total DNA was subjected to PCR ( 25 cycles) using the following set of primers: MT-B (forward) 5'-GGAACAAGCATCAAG CAC-3' and MT-B' (reverse) 5'-GGCCATGGGTATGTTGTT-3' (Genosys Biotechnologies Inc., The Woodlands, TX, USA) as previously described (47). Auxotrophy on uridine and pyruvate for survival, a characteristic feature of Rho- cells (53), also confirmed the Rho- status of the cells.

Anti-Fas and cisplatin-mediated apoptosis. Cells were plated in 96-well plates at $2 \times 10^{4}$ (DBTRG-O5MG) or 4x104 (U87). After the cells were allowed to adhere for 2-4 h, media were replaced with fresh complete medium, and cells were incubated with various concentrations of mouse monoclonal anti-Fas antibodies (clone CH-11; Upstate Biotechnology, Lake Placid, NY, USA) for $24 \mathrm{~h}$ (U87) or $72 \mathrm{~h}$ (DBTRG-O5MG). Wells containing no treatment or mouse IgM (Sigma Chemical Company) served as controls. Cells were harvested, washed in PBS and incubated at $4^{\circ} \mathrm{C}$ overnight in hypotonic fluorochrome solution $(0.1 \%$ sodium citrate, $0.1 \%$ Triton X-100 and $50 \mu \mathrm{g} / \mathrm{ml}$ propidium iodide). A FACScan flowcytometer (Coulter, Miami, FL, USA) was used to quantify the percentage of cells undergoing apoptosis as previously described (54). Nuclei that fluoresced below the G1 DNA represented apoptotic nuclei and are presented as the percentage of apoptosis (5,000 gated events). Death induced by cisplatin (Sigma Chemical Company) was analyzed as above by incubating $4 \times 10^{4}$ cells with $20 \mu \mathrm{M}$ cisplatin for $42-48 \mathrm{~h}$. Wells with vehicle alone served as controls.

Cell surface Fas expression. Fas expression at the cell surface was analyzed using flow cytometry. Adherent cells were disassociated into a single-cell suspension with $10 \mathrm{mM}$ EDTA in PBS. The cells were then pelleted, washed once in PBS and resuspended in flow cytometry buffer (PBS containing $1 \%$ FBS). Cells $\left(10^{6}\right)$ were incubated with anti-Fas antibodies or an isotype $(20 \mu \mathrm{g} / \mathrm{ml})$ in flow cytometry buffer for $30 \mathrm{~min}$ on ice. Cells were then washed with flow cytometry buffer, incubated with FITC-conjugated anti-mouse IgG for $30 \mathrm{~min}$ on ice, washed once with flow cytometry buffer, resuspended in flow cytometry buffer and analyzed using a FACScan flow cytometer. A minimum of 20,000 gated events per sample was analyzed.

Treatment of cells with mitochondrial respiratory chain complex inhibitors. DBTRG-O5MG and U87 cells were incubated with non-lethal concentrations of rotenone $(0.098 \mu \mathrm{M})$, thenoyltrifluoroacetone $(31.25 \mu \mathrm{M})$, antimycin $\mathrm{A}(12.5 \mu \mathrm{M})$, sodium azide $(500 \mu \mathrm{M})$, oligomycin $\mathrm{B}(1.56 \mu \mathrm{M})$ and membrane potential disrupting agent valinomycin $(0.0037 \mu \mathrm{M})$. After $24 \mathrm{~h}$, Fas expression on the cell surface was determined as noted. A non-lethal concentration of these inhibitors was previously determined by clonogenic survival assay of the cells treated with various concentrations of each of the inhibitors (data not shown). To assess the inhibition of the mitochondrial function by mitochondrial complex inhibitors, cytochrome c oxidase activity was measured by treating the isolated mitochondria with one of the complex inhibitors (500 $\mu \mathrm{M}$ sodium azide). All chemicals used were from Sigma Chemical Company.

Isolation and purification of mitochondria. Mitochondria were isolated as described (4). Briefly, cells were harvested, washed and stored at $-70^{\circ} \mathrm{C}$ until use for the isolation of mitochondria. Cells were then resuspended in ice-cold buffer $(250 \mathrm{mM}$ sucrose, $20 \mathrm{mM}$ HEPES-NaOH, $10 \mathrm{mM} \mathrm{KCl}, 1.5 \mathrm{mM} \mathrm{MgCl}{ }_{2}$, $1 \mathrm{mM}$ EDTA, $1 \mathrm{mM}$ DTT, $17 \mu \mathrm{g} / \mathrm{ml}$ phenylmethylsulfonylfluoride, $8 \mu \mathrm{g} / \mathrm{ml}$ aprotinin, $2 \mu \mathrm{g} / \mathrm{ml}$ leupeptin, $1 \mu \mathrm{g} / \mathrm{ml}$ chymostatin, $1 \mu \mathrm{g} / \mathrm{ml}$ pepstatin and $1 \mu \mathrm{g} / \mathrm{ml}$ antipain). Cells were homogenized using a tight fitting dounce homogenizer, 20-30 strokes on ice. After pelleting the nuclei and unlysed cells at $100 \mathrm{x} \mathrm{g}$ for $10 \mathrm{~min}$ at $4^{\circ} \mathrm{C}$ in a refrigerated microcentrifuge (Savant Instruments, Inc., Farmingdale, NY, USA), the mitochondria were pelleted at $10,000 \times \mathrm{g}$ for $25 \mathrm{~min}$ at $4^{\circ} \mathrm{C}$ in an ultracentrifuge (Beckman Instruments Inc., Palo Alto, CA, USA). Mitochondria that banded at a density of 1.035 (as monitored by density marker beads) were collected.

SDS PAGE and Western blotting. Proteins of mitochondria and the whole cell homogenate were estimated using bicinchoninic acid (Sigma Chemical Company). Crude mitochondria, whole cell homogenate and aliquots of purified mitochondria $(50 \mu \mathrm{g})$ were boiled in Laemmli sample buffer and separated using 12\% SDS PAGE. Proteins were blotted onto nitrocellulose, and the Fas protein was detected using rabbit polyclonal anti-Fas antibody (C-20; Santa Cruz Biotechnology, Inc., Santa Cruz, CA, USA) at a 1:1,000 dilution. A goat anti-rabbit antibody conjugated with horseradish peroxidase (Santa Cruz Biotechnology) was used at a 1:10,000 dilution to detect immunoreactive proteins, which were visualized by enhanced chemoluminescence (Amersham Pharmacia Biotech Inc., Piscataway, NJ, USA).

Determination of ATP levels. ATP levels were determined using the Sigma kit 366 (Sigma Chemical Company) according to the manufacturer's instructions, with $10^{6}$ cells.

Statistics. The results were calculated as the arithmetic mean \pm SEM. The student's t-test was used to compare the groups. $\mathrm{p}<0.05$ was regarded as significant. 
Table I. Cellular ATP levels.

\begin{tabular}{lcc}
\hline Cells & Rho $^{+}$ & Rho $^{-}$ \\
\hline U87 & $16.3 \pm 1.20$ & $14.3 \pm 1.45$ \\
DBTRG-O5MG & $14.7 \pm 0.33$ & $12.7 \pm 1.33$ \\
\hline
\end{tabular}

Values expressed as $\mu \mathrm{g} / 10^{6}$ cells.

A

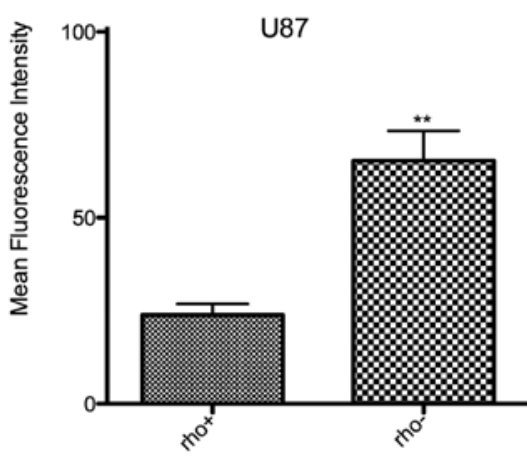

B

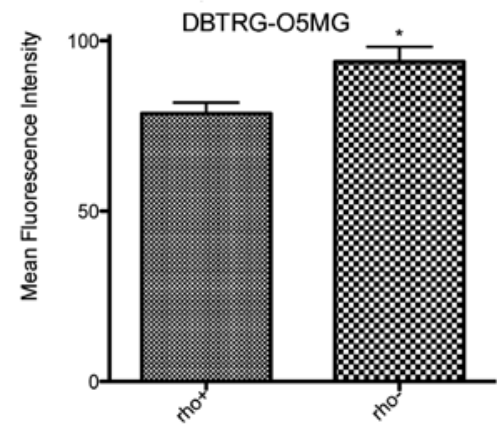

Figure 1. Fas expression in the (A) U87 and (B) DBTRG-O5MG glioma cell lines. Rho- cells expressed higher levels of Fas compared to the parental $\mathrm{Rho}^{+}$cells, as determined by flow cytometry $\left({ }^{*} \mathrm{p}<0.045,{ }^{* *} \mathrm{p}<0.0001\right)$.

\section{Results}

\section{Characterization of Rho cells}

$P C R$. DBTRG-05MG and U87 cells were depleted of the mtDNA by culturing in a medium containing $30 \mathrm{ng} / \mathrm{ml} \mathrm{EtBr}$. The Rho- status of the mtDNA-depleted DBTRG-05MG and U87 cells was determined by PCR using a mitochondrialspecific DNA primer. A 2.6-kb mtDNA amplified from the DNA of $\mathrm{Rho}^{+}$cells was not observed from the DNA of the mtDNA-depleted DBTRG-O5MG and U87 cells by PCR; the identity of the PCR-amplified products was confirmed by sequencing (data not shown). These results indicate that the Rho- DBTRG-05MG and U87 cells did not harbor mtDNA.

Auxotrophy to uridine and pyruvate. The mtDNA-depleted cells were evaluated for auxotrophic dependence on uridine and pyruvate. The mtDNA-depleted cells died after 7-10 days in the culture medium lacking uridine and pyruvate. The $\mathrm{Rho}^{+}$cells continued to divide and propagate during the entire period when loss of viability was noted in the respective Rho cells. Taken together, these results confirm the Rho- status of EtBr-treated DBTRG-05MG and U87 cells.

Measurement of ATP levels. In order to assess the effect of the loss of mtDNA on ATP levels, cellular ATP was measured
Table II. Effect of mitochondrial complex inhibitors on the surface expression of Fas.

\begin{tabular}{lccccc}
\hline Treatment & \multicolumn{2}{c}{$\begin{array}{c}\text { Mean \% increase } \\
\text { over control }\end{array}$} & & \multicolumn{2}{c}{$\begin{array}{c}\text { Significance (p-value } \\
\text { vs. untreated cells) }\end{array}$} \\
\cline { 2 - 3 } \cline { 6 - 6 } & U87 & $\begin{array}{c}\text { DBTRG- } \\
\text { O5MG }\end{array}$ & & U87 & $\begin{array}{c}\text { DBTRG- } \\
\text { O5MG }\end{array}$ \\
\hline Rotenone & 70 & 35 & & 0.0001 & 0.0161 \\
Antimycin A & 48 & - & & 0.0012 & NS \\
Oligomycin & - & 37 & & - & 0.0010 \\
Valinomycin & 43 & 32 & & 0.0070 & 0.0010 \\
\hline
\end{tabular}

NS, not significant.

in the DBTRG-05MG and $\mathrm{U} 87 \mathrm{Rho}^{+}$cells and their respective Rho- cells (Table I). The ATP levels of DBTRG-05MG Rho ${ }^{+}$ and $\mathrm{Rho}^{-}$cells were $14.7 \pm 0.33$ and $12.7 \pm 1.33 \mu \mathrm{g} / 10^{6}$ cells, respectively, and the ATP levels of $\mathrm{U}^{6} \mathrm{Rho}^{+}$and Rho- cells were $16.3 \pm 1.20$ and $14.3 \pm 1.45 \mu \mathrm{g} / 10^{6}$ cells, respectively. No significant differences were detected in the amount of ATP in Rho- cells as compared to their respective $\mathrm{Rho}^{+}$cells.

Evaluation of cell surface Fas. The cell surface expression of Fas was determined in the $\mathrm{Rho}^{+}$and $\mathrm{Rho}^{-}$cells in order to assess its association with the depletion of mtDNA. Fas expression on the cell surface was found to be enhanced in the Rho- DBTRG-O5MG and U87 cells as compared to their respective $\mathrm{Rho}^{+}$cells (Fig. 1). There was a 2.7-fold increase in the cell surface expression of Fas in the U87 Rho- cells $(\mathrm{p}<0.0001)$ and a 19\% increase in surface Fas in the DBTRGO5MG Rho- cells $(\mathrm{p}<0.045)$ as compared to the $\mathrm{Rho}^{+}$cells

DBTRG-O5MG and U87 $\mathrm{Rho}^{+}$cells were then treated with mitochondrial respiratory chain complex inhibitors (Table II). Treatment with rotenone increased the level of Fas in the U87 cells by $70 \%(\mathrm{p}<0.0001)$ and in the DBTRGO5MG cells by $35 \%(\mathrm{p}<0.0161)$ as compared to the untreated cells. Valinomycin was also observed to increase Fas expression by over $30 \%$ in both cell lines $(\mathrm{p}<0.001$, U87 cells; $\mathrm{p}<0.007$, DBTRG-05MG cells) as compared to untreated cells. Moreover, antimycin A increased the level of Fas in the U87 cells $(48 \%, p<0.0012)$, and oligomycin B increased the cell surface Fas in the DBTRG-05MG cells (37\%, p <0.001). These results suggest that the depletion of mtDNA and the inhibition of mitochondrial respiratory chain complex function alter the expression of Fas at the surface of glioma cells.

Effect of anti-Fas antibodies on DBTRG-O5MG and U87 cells. Fas-mediated apoptosis was evaluated in the $\mathrm{Rho}^{+}$and mtDNA-depleted DBTRG-O5MG and U87 cells by FACS analysis after the cells were subjected to apoptosis-inducing anti-Fas antibodies (Fig. 2). Sensitivity of the DBTRG-O5MG cells to anti-Fas antibodies at a concentration ranging between 15 and $1,000 \mathrm{ng} / \mathrm{ml}$ was similar in the $\mathrm{Rho}^{+}$and $\mathrm{Rho}^{-}$cells (Fig. 2A). Similarly, in the U87 Rho- cells, the percentage of cells undergoing apoptosis when treated with anti-Fas anti- 
A

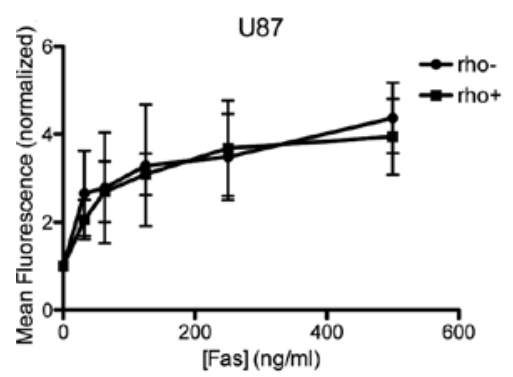

B

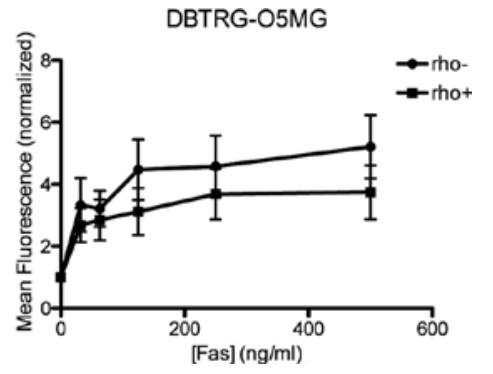

Figure 2. Fas-mediated apoptosis of the (A) U87 and (B) DBTRG-O5MG glioma cell lines. $\mathrm{Rho}^{+}$and Rho- cells were treated with the anti-Fas antibody $\mathrm{CH} 11$ to induce apoptosis; no difference was noted in the apoptosis dose response between cells that harbored mtDNA and those that were depleted of mtDNA.

A

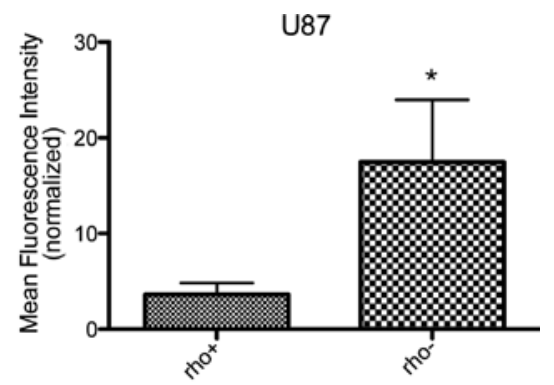

B

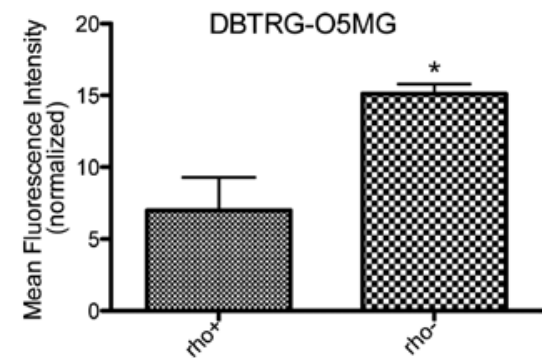

Figure 3. Cisplatin (CDDP)-induced apoptosis of the (A) U87 and (B) DBTRG-O5MG glioma cell lines. $\mathrm{Rho}^{+}$and $\mathrm{Rho}^{-}$cells were exposed to $20 \mu \mathrm{M}$ CDDP. Both Rho- cell lines revealed increased sensitivity to the effects of CDDP $($ p $\mathrm{p}<0.0001)$.

bodies was not significantly different compared to the $\mathrm{Rho}^{+}$ cells (Fig. 2B).

Sensitivity of DBTRG-O5MG and U87 Rho ${ }^{+}$and their respective Rho- cells to cisplatin. In order to assess the sensitivity of DBTRG-05MG and U87 $\mathrm{Rho}^{+}$and their respective Rho' cells to cytotoxic agents, cells were treated with cisplatin $(20 \mu \mathrm{M})$ and subjected to FACS analysis (Fig. 3). DBTRG-O5MG and U87 Rho- cells were more sensitive to the apoptosis-inducing effects of cisplatin; the U87 Rho- cells revealed a 4-fold and the DBTRG-O5MG cells a 2-fold increase in sensitivity
A

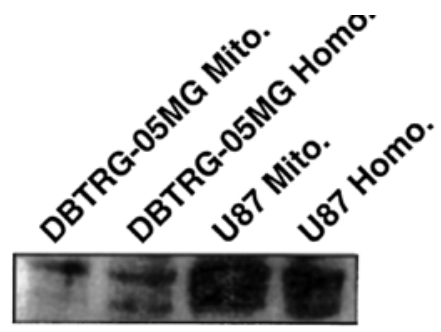

B

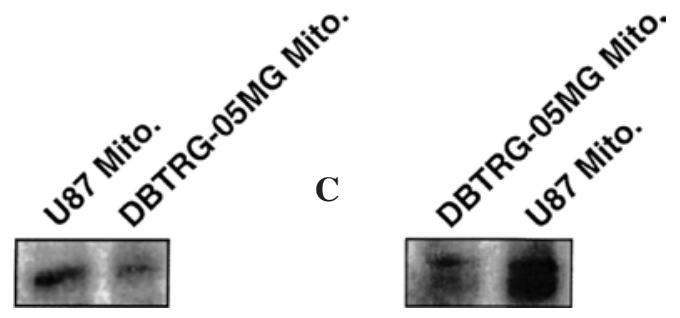

Figure 4. Western blots of protein fractions obtained from glioma cells. Mitochondria were isolated and purified from glioma cell lines. (A) Crude homogenates including the mitochondrial fraction. (B) Percoll purified mitochondrial fraction probed with cytochrome c oxidase antibody. (C) Percoll-purified mitochondrial fraction probed with anti-Fas antibody. Prominent Fas staining was observed.

to apoptosis compared to the $\mathrm{Rho}^{+}$cells at $20 \mu \mathrm{M}$. Taken together, these results suggest that the depletion of mtDNA leads to an increased sensitivity of Rho- cells to cisplatin.

Fas protein and mitochondria. Western blot analysis of the mitochondria and whole cell homogenate using Fas antibodies revealed a predominant $43-\mathrm{kDa}$ Fas protein band (with associated glycoforms) in both the DBTRG-O5MG and U87 glioma cells (Fig. 4A). With percoll purification of mitochondria alone, similar bands were noted in the immunoblots when probed with the anti-Fas antibody (Fig. 4C); probes to cytochrome c identified the mitochondrial fraction (Fig. 4B), while probes to actin did not reveal staining (data not shown).

\section{Discussion}

Previous studies suggest an involvement of mtDNA in sensitivity to apoptosis (43,50-52). The present study was undertaken to assess the relationship between mitochondria and Fas in mediating apoptosis. We found that, while the depletion of mtDNA was associated with an increase in surface Fas in both GBM cell lines, sensitivity to anti-Fas antibodies was not increased in the Rho- cells as compared to the $\mathrm{Rho}^{+}$ cells. However, the sensitivity to cisplatin was increased in the Rho- cells as compared to the $\mathrm{Rho}^{+}$cells, in agreement with results from previous studies $(50,51)$. There may be several reasons for this observation. The degree of sensitivity to Fas-mediated apoptosis is reported to be dependent on several factors, including expression of the functional Fas molecule on the cell surface $(56,57)$, mutations in the death domain of Fas (33), expression of soluble Fas (34), reduced expression of Fas (27), intracellular signaling cascade activation upon Fas ligation $(40,58)$, expression of the components of DISC and inhibition of essential signaling pathways $(28,32,35-39,41)$. It has been revealed that, although Fas antigen is expressed on numerous myeloma cell lines, only some respond to the anti-Fas/Fas-ligand $(59,60)$. Indeed, although the mechanism 
for increased Fas expression with no concomitant increase in sensitivity to anti-Fas antibodies is not clearly understood, it is possible that the observed increases in Fas expression do not result in enhanced death due to saturation of signaling pathways or overexpression of functionally inactive Fas. It can also be speculated that the inhibition of mitochondria via $\mathrm{Rho}^{-}$status in these glioma cells also reduces the release of intrinsic factors, including SMAC/DIABLO and/or Htra2; in this way, the inhibition of XIAP is released, thus inhibiting caspase-3 and -7 either before or after Fas-induced activation via DISC/caspase- 8 and -10 . It would be anticipated that the linkage to the intrinsic pathway via truncated BID to BAK and BAX might be impaired at the level of mitochondria due to Rho ${ }^{-}$status. Nonetheless, the fact that cisplatin-induced apoptosis still occurs - and with higher levels of sensitivity in $\mathrm{Rho}^{-}$vs. $\mathrm{Rho}^{+}$cells - suggests that the mechanism of at least the cytotoxic drug-induced apoptosis is intact, and the mitochondria, acting as a 'rheostat' to sensitivity at least at the level of the intrinsic pathway, continue to be maintained. The expression of components of the Fas signaling pathway in $\mathrm{Rho}^{-}$cells is being investigated in order to determine the mechanism of the observed ineffective death signaling by Fas in Rho- cells.

Notably, in a functional model of Rho- cells, Leber hereditary optic neuropathy tissues with mutations at mtDNA positions 11778 and 3460 were found to have increased sensitivity to the engagement of Fas compared to normal tissue controls (61). This suggests that mitochondrial dysfunction at the level of the tumor cell may not be sufficient to facilitate apoptosis in such cells per se, but may be in such mitochondrial diseases. This may be related to more complex factors, including the BAX/ BCL2 ratio (62) or the release of mitochondrial apoptosis factors (63). Furthermore, although the up-regulation of Fas was noted in cells treated with cisplatin and other cytotoxic agents (64-67), drug-induced apoptosis occurs independently of the Fas/Fas ligand system (68-70). The increased sensitivity to cisplatin of the Rho- DBTRG-O5MG and U87 cells appears to be independent of the enhanced Fas expression and, in these GBM cells, confirms previous studies in Rho- cells (50-52).

Treatment of $\mathrm{Rho}^{+}$cells with mitochondrial respiratory chain complex inhibitors enhanced the levels of cell surface Fas expression. The variation of response, both at the level of the different degrees of Fas expression noted vs. Rho- cells and between the independent pharmacologic inhibitors, may be a result of the dose of complex inhibitors used, which allowed cells to survive. Moreover, differential effects of antimycin A and oligomycin B observed on the GBM cells may be due to the respective amounts of functional protein present and/or due to deletions and mutations in mtDNA. Nonetheless, these observations support the increased expression of Fas on the surface of Rho- cells, depleted of mtDNA. Indeed, cells with impaired mitochondrial function were found to have increased levels of Fas mRNA (71), corroborating the present observations.

Due to the relationship between mtDNA status and Fas surface expression, we evaluated the localization of Fas to the mitochondrial protein fraction as determined by whole cell homogenates and percoll-purified mitochondria. Notably, Fas was found to segregate with mitochondrial protein in the purified percoll fraction. While it is only speculated on the role of Fas therein, many proteins associated with apoptosis are found within the mitochondria (22). The ability of the mitochondria to regulate manifestations of the extrinsic pathway is related to the mitochondrial distribution of Fas; there is both supporting $(42,71)$ and refuting $(24,34)$ evidence to this effect. Further evaluation of the relationship(s) between the extrinsic and intrinsic pathways of apoptosis, particularly in relation to Fas protein expression, is of interest in this regard.

In conclusion, our studies show that the depletion of mtDNA alters the expression of cell surface Fas. This is supported by the results obtained upon treatment of the parental cells $\left(\mathrm{Rho}^{+}\right)$ with mitochondrial respiratory chain complex inhibitors, wherein altered expression of cell surface Fas was observed. The sensitivity of Rho- cells to cisplatin, but not to anti-Fas antibodies, was found to be enhanced when compared to $\mathrm{Rho}^{+}$ cells, despite similar alteration at the mitochondrial level.

\section{Acknowledgements}

We thank C. Kruse for the DBTRG-O5MG cell line, B. Laxman and L. Miller for technical assistance and S. Munson for administrative assistance. This study was supported by grants from the National Cancer Institute (CA73916) and the American Society of Clinical Oncology.

\section{References}

1. Henkart PA and Grinstein S: Apoptosis: mitochondria resurrected? J Exp Med 183: 1293-1295, 1996.

2. Kroemer G, Zamzami N and Susin SA: Mitochondrial control of apoptosis. Immunol Today 18: 44-51, 1997.

3. Green DR and Reed JC: Mitochondria and apoptosis. Science 281: 1309-1312, 1998.

4. Cavalli LR and Liang BC: Mutagenesis, tumorigenicity and apoptosis: are the mitochondria involved? Mutat Res 398: 19-26, 1998.

5. Newmeyer DD, Farschon DM and Reed JC: Cell-free apoptosis in Xenopus egg extracts: inhibition by Bel-2 and requirement for an organelle fraction enriched in mitochondria. Cell 79: 353-364, 1994.

6. Vayssiere JL, Petit PX, Risler Y and Mignotte B: Commitment to apoptosis is associated with changes in mitochondrial biogenesis and activity in cell lines conditionally immortalized with simian virus 40. Proc Natl Acad Sci USA 91: 11752-11756, 1994.

7. Cossarizza A, Franceschi C, Monti D, et al: Protective effect of $\mathrm{N}$-acetylcysteine in tumor necrosis factor-alpha-induced apoptosis in U937 cells: the role of mitochondria. Exp Cell Res 220: 232-240, 1995.

8. Petit PX, Lecoeur H, Zorn E, et al: Alterations in mitochondrial structure and function are early events of dexamethasoneinduced thymocyte apoptosis. J Cell Biol 130: 157-167, 1995.

9. Castedo M, Macho A, Zamzani N, et al: Mitochondrial perturbations define lymphocytes undergoing apoptotic depletion in vivo. Eur J Immunol 25: 3277-3284, 1995.

10. Zamzami N, Marchetti P, Castedo M, et al: Sequential reduction of mitochondrial transmembrane potential and generation of reactive oxygen species in early programmed cell death. J Exp Med 182: 367-377, 1995.

11. ZamzamiN, Marchetti P, Castedo M, et al: Mitochondrial control of nuclear apoptosis. J Exp Med 183: 1533-1544, 1996.

12. Shimizu S, Eguchi Y, Kamiike W, et al. Bcl-2 blocks loss of mitochondrial membrane potential while ICE inhibitors act at a different step during inhibition of death induced by respiratory chain inhibitors. Oncogene 13: 21-29, 1996.

13. Susin SA, Zamzami N, Castedo M, et al: Bcl-2 inhibits the mitochondrial release of an apoptogenic protease. J Exp Med 184: 1331-1341, 1996.

14. Zamzami N, Marchetti P, Castedo M, et al: Inhibitors of permeability transition interfere with the disruption of the mitochondrial transmembrane potential during apoptosis. FEBS Lett 384: 53-57, 1996. 
15. Boise LH and Thompson CB: Bcl-x(L) can inhibit apoptosis in cells that have undergone Fas-induced protease activation. Proc Natl Acad Sci USA 94: 3759-3764, 1997.

16. Kroemer G: The proto-oncogene $\mathrm{Bcl}-2$ and its role in regulating apoptosis. Nat Med 3: 614-620, 1997.

17. Stuart RA and Neupert W: Apocytochrome c: an exceptional mitochondrial precursor protein using an exceptional import pathway. Biochimie 72: 115-121, 1990.

18. Kluck RM, Bossy-Wetzel E, Green DR and Newmeyer DD: The release of cytochrome $\mathrm{c}$ from mitochondria: a primary site for Bcl-2 regulation of apoptosis. Science 275: 1132-1136, 1997.

19. Mancini M, Nicholson DW, Roy S, et al: The caspase-3 precursor has a cytosolic and mitochondrial distribution: implications for apoptotic signaling. J Cell Biol 140: 1485-1495, 1998.

20. Susin SA, Lorenzo HK, Zamzani N, et al: Molecular characterization of mitochondrial apoptosis-inducing factor. Nature 397: 441-446, 1999

21. Susin SA, Lorenzo HK, Zamzani N, et al: Mitochondrial release of caspase-2 and -9 during the apoptotic process. J Exp Med 189. 381-394, 1999

22. D'Amelio M, Tino E and Cecconi F: The apoptosome emerging insights and new potential targets for drug design. Pharm Res 25: 740-751, 2008

23. Bossy-Wetzel E, Newmeyer DD and Green DR: Mitochondrial cytochrome $\mathrm{c}$ release in apoptosis occurs upstream of DEVD-specific caspase activation and independently of mitochondrial transmembrane depolarization. EMBO J 17: 37-49, 1998.

24. Suzuki A, Tsutomi Y, Yamamoto N, Shibutani T and Akahane K: Mitochondrial regulation of cell death: mitochondria are essentia for procaspase 3-p21 complex formation to resist Fas-mediated cell death. Mol Cell Biol 19: 3842-3847, 1999.

25. Trauth BC, Klas C, Peters AM, et al: Monoclonal antibody-mediated tumor regression by induction of apoptosis. Science 245: 301-305, 1989

26. Leithauser F, Dhein J, Mechtersheimer G, et al: Constitutive and induced expression of APO-1, a new member of the nerve growth factor/tumor necrosis factor receptor superfamily, in normal and neoplastic cells. Lab Invest 69: 415-429, 1993.

27. Moller P, Koretz K, Leithauser F, et al: Expression of APO-1 (CD95), a member of the NGF/TNF receptor superfamily, in normal and neoplastic colon epithelium. Int J Cancer 57: 371-377, 1994.

28. Weller M, Malipiero U, Rensing-Ehl A, Barr PJ and Fontana A: Fas/APO-1 gene transfer for human malignant glioma. Cancer Res 55: 2936-2944, 1955.

29. Nagata S and Golstein P: The Fas death factor. Science 267: 1449-1456, 1995.

30. French LE, Hahne M, Viard I, et al: Fas and Fas ligand in embryos and adult mice: ligand expression in several immune-privileged tissues and coexpression in adult tissues characterized by apoptotic cell turnover. J Cell Biol 133: 335-343, 1996.

31. Houghton JA, Harwood FG, Gibson AA and Tillman DM: The fas signaling pathway is functional in colon carcinoma cells and induces apoptosis. Clin Cancer Res 3: 2205-2209, 1997.

32. Mahmood Z and Shulka Y: Death receptors: targets for cancer therapy. Exp Cell Res 316: 887-899, 2010.

33. Itoh $\mathrm{N}$ and Nagata $\mathrm{S}$ : A novel protein domain required for apoptosis. Mutational analysis of human Fas antigen. J Biol Chem 268: 10932-10937, 1993.

34. Cheng J, Zhou T, Liu C, et al: Protection from Fas-mediated apoptosis by a soluble form of the Fas molecule. Science 263 1759-1762, 1994.

35. Sato T, Irie $S$, Kitada $S$ and Reed JC: FAP-1: a protein tyrosine phosphatase that associates with Fas. Science 268: 411-415, 1995 .

36. Hughes SJ, Nambu Y, Soldes OS, et al: Fas/APO-1 (CD95) is not translocated to the cell membrane in esophageal adenocarcinoma. Cancer Res 57: 5571-5578, 1997.

37. Irmler M, Thorne M, Hahne M, et al: Inhibition of death receptor signals by cellular FLIP. Nature 388: 190-195, 1997.

38. Rokhlin OW, Bishop GA, Hostager BS, et al: Fas-mediated apoptosis in human prostatic carcinoma cell lines. Cancer Res 57: $1758-1768,1997$

39. Tillman DM, Harwood FG, Gibson AA and Houghton JA: Expression of genes that regulate Fas signalling and Fas-mediated apoptosis in colon carcinoma cells. Cell Death Differ 5: 450-457, 1998.

40. Owen-Schaub LB, Radinsky R, Kruzel E, Berry K and Yonehara S: Anti-Fas on nonhematopoietic tumors: levels of Fas/ APO-1 and bcl-2 are not predictive of biological responsiveness. Cancer Res 54: 1580-1586, 1994.
41. Holmstrom TH, Tran SE, Johnson VL, et al: Inhibition of mitogen-activated kinase signaling sensitizes HeLa cells to Fas receptor-mediated apoptosis. Mol Cell Biol 19: 5991-6002, 1999.

42. Scaffidi C, Fulda S, Srinivasan A, et al: Two CD95 (APO-1/Fas) signaling pathways. EMBO J 17: 1675-1687, 1998.

43. Heerdt BG, Houston MA and Augenlicht LH: Short-chain fatty acid-initiated cell cycle arrest and apoptosis of colonic epithelia cells is linked to mitochondrial function. Cell Growth Differ 8: 523-532, 1997.

44. Jacobson MD, Burne JF, King MP, et al: Bcl-2 blocks apoptosis in cells lacking mitochondrial DNA. Nature 361: 365-369, 1993.

45. Jacobson MD and Raff MC: Programmed cell death and Bcl-2 protection in very low oxygen. Nature 374: 814-816, 1995.

46. Shimizu S, Eguchi Y, Kosaka H, et al: Prevention of hypoxia-induced cell death by Bcl-2 and Bel-xL. Nature 374: 811-813, 1995.

47. Gamen S, Anel A, Montoya J, et al: mtDNA-depleted U937 cells are sensitive to TNF and Fas-mediated cytotoxicity. FEBS Lett 376: $15-18,1995$

48. Marchetti P, Susin SA, Decaudin D, et al: Apoptosis-associated derangement of mitochondrial function in cells lacking mitochondrial DNA. Cancer Res 56: 2033-2038, 1996.

49. Schulze-Osthoff K, Beyaert R, Vandevoorde V, Haegeman G and Fiers W: Depletion of the mitochondrial electron transport abrogates the cytotoxic and gene-inductive effects of TNF. EMBO J 12: 3095-3104, 1993.

50. Cavalli LR, Varella-Garcia M and Liang BC: Diminished tumorigenic phenotype after depletion of mitochondrial DNA. Cell Growth Differ 8: 1189-1198, 1997.

51. Liang $\mathrm{BC}$ and Ullyatt $\mathrm{E}$ : Increased sensitivity to cis-diamminedichloroplatinum induced apoptosis with mitochondrial DNA depletion. Cell Death Differ 5: 694-701, 1998.

52. Liang BC and Ullyatt E: Chemosensitization of glioblastoma cells to bis-dichloroethylnitrosourea with tyrphostin AG17. Clin Cancer Res 4: 773-781, 1998

53. King MP and Attardi G: Isolation of human cell lines lacking mitochondrial DNA. Methods Enzymol 264: 304-313, 1996.

54. Nicoletti I, Migliorati G, Pagliacci MC, Grignani F and Riccardi C: A rapid and simple method for measuring thymocyte apoptosis by propidium iodide staining and flow cytometry. J Immunol Methods 139: 271-279, 1991

55. Vander Heiden MG, Chandel NS, Williamson EK, Schumacker PT and Thompson CB: Bcl-xL regulates the membrane potential and volume homeostasis of mitochondria. Cell 91: 627-637, 1997

56. Watanabe-Fukunaga R, Brannan CI, Copeland NG, Jenkins NA and Nagata $\mathrm{S}$ : Lymphoproliferation disorder in mice explained by defects in Fas antigen that mediates apoptosis. Nature 356: 314-317, 1992.

57. Nagata S and Suda T: Fas and Fas ligand: 1pr and gld mutations. Immunol Today 16: 39-43, 1995

58. Wong GH and Goeddel DV: Fas antigen and p55 TNF receptor signal apoptosis through distinct pathways. J Immunol 152: 1751-1755, 1994.

59. Shima Y, Nishimoto N, Ogata A, et al: Myeloma cells express Fas antigen/APO-1 (CD95) but only some are sensitive to anti-Fas antibody resulting in apoptosis. Blood 85: 757-764, 1995.

60. Westendorf JJ, Lammert JM and Jelinek DF: Expression and function of Fas (APO1/CD95) in patient myeloma cells and myeloma cell lines. Blood 85: 3566-3576, 1995.

61. Danielson SR, Wong A, Carelli V, Martinuzzi A, Schapira AH and Cortopassi GA: Cells bearing mutations causing Leber's hereditary optic neuropathy are sensitized to Fas-Induced apoptosis. J Biol Chem 277: 5810-5815, 2002.

62. Raisova M, Hossini AM, Eberle J, Riebeling C, Wieder T, Sturm I, Daniel PT, Orfanos CE and Geilen CC: The Bax/Bcl-2 ratio determines the susceptibility of human melanoma cells to CD95/Fas-mediated apoptis. J Invest Dermatol 117: 333-340, 2001.

63. Maas C, Verbrugge I, De Vries E, Savich G, van de Kooij LW, Tait SW and Borst J: Smac/DIABLO release from mitochondria and XIAP inhibition are essential to limit clonogencity of Type I tumor cells after TRAIL receptor stimulation. Cell Death Differ 17: 1613-1623, 2010.

64. Friesen C, Herr I, Krammer PH and Debatin KM: Involvement of the CD95 (APO-1/FAS) receptor/ligand system in druginduced apoptosis in leukemia cells. Nat Med 2: 574-577, 1996. 
65. Matsumoto Y, Hayakawa A, Tamada Y, Mori H and Ohashi M: Upregulated expression of Fas antigen on cultured human keratinocytes with induction of apoptosis by cisplatin. Arch Dermatol Res 288: 267-279, 1996.

66. Fulda S, Sieverts H, Friesen C, Herr I and Debatin KM: The CD95 (APO-1/Fas) system mediates drug-induced apoptosis in neuroblastoma cells. Cancer Res 57: 3823-3829, 1997.

67. Muller M, Strand S, Hug H, et al: Drug-induced apoptosis in hepatoma cells is mediated by the CD95 (APO-1/Fas) receptor/ ligand system and involves activation of wild-type p53. J Clin Invest 99: 403-413, 1997.

68. Eischen CM, Kottke TJ, Martins LM, et al: Comparison of apoptosis in wild-type and Fas-resistant cells: chemotherapy-induced apoptosis is not dependent on Fas/Fas ligand interactions. Blood 90: 935-943, 1997.
69. Villunger A, Egle A, Kos M, et al: Drug-induced apoptosis is associated with enhanced Fas (Apo-1/CD95) ligand expression but occurs independently of' Fas (Apo-1/CD95) signaling in human T-acute lymphatic leukemia cells. Cancer Res 57: 3331-3334, 1997.

70. Verbrugge I, Maas C, Heijkoop M, Verheij and Borst J: Radiation and anticancer drugs can facilitate mitochondrial bypass by CD95/FAS via c-FLIP downregulation. Cell Death Differ 17: 551-561, 2010.

71. Asoh S, Mori T, Hayashi J and Ohta S: Expression of the apoptosis-mediator Fas is enhanced by dysfunctional mitochondria. J Biochem 120: 600-607, 1996. 